\title{
Metal Acetylacetonates as General Precursors for the Synthesis of Early Transition Metal Oxide Nanomaterials
}

\author{
Amanda L. Willis, ${ }^{1}$ Zhuoying Chen, ${ }^{2}$ Jiaqing He, ${ }^{3}$ Yimei Zhu, ${ }^{3}$ Nicholas J. Turro, ${ }^{1}$ and Stephen O'Brien $^{2}$ \\ ${ }^{1}$ Department of Chemistry, Columbia University, New York, NY 10027, USA \\ ${ }^{2}$ Department of Applied Physics and Applied Mathematics, Columbia University, New York, NY 10027, USA \\ ${ }^{3}$ Department of Materials Science, Brookhaven National Lab, Upton, NY 11973, USA
}

Received 18 December 2006; Accepted 27 April 2007

Recommended by Butrand I. Lee

A versatile, convenient, and nontoxic solvothermal method for the synthesis of nanocrystalline iron, chromium, and manganese oxides is described. This method employs the reactions of metal acetylacetonate precursors and oxygen-containing solvents in a reaction to prepare metal oxide nanoparticles. Characterization of these nanocrystalline materials was carried out employing transmission electron microscopy (TEM), high-resolution TEM (HRTEM), X-ray diffraction (XRD), and elemental analysis.

Copyright (c) 2007 Amanda L. Willis et al. This is an open access article distributed under the Creative Commons Attribution License, which permits unrestricted use, distribution, and reproduction in any medium, provided the original work is properly cited.

\section{INTRODUCTION}

Transition metal oxide nanoparticles represent a broad class of materials that have been researched extensively due to their interesting catalytic, electronic, and magnetic properties, and wide scope of potential applications, such as magnetic resonance imaging (MRI) [1], solar cells [2], and heterogeneous catalysis $[3,4]$. The literature describes a range of approaches for synthesizing metal oxide nanoparticles from various inorganic or organometallic precursors, driven by the rapid development of the nanosciences during the past two decades. Thermal decomposition procedures which produce uniform nanoparticles are widely popular; typical starting materials include metal acetylacetonates [5], metal cupferronates [6], metal alkoxides [7], metal carbonyls [8], and metal halides [9]. These methods in general are of limited synthetic scope for metal oxide synthesis.

Recently, there has been a focus on developing more general methods $[5,10-14]$ that can be applied to preparation of a variety of metal oxides. This is important from an industrial scale-up perspective because a general synthesis of many oxides will allow the use of a single reactor as opposed to separate set-ups. We focused our efforts on the development of a method to prepare a variety of metal oxide nanoparticles from a common set of precursors-metal acetylacetonates. A convenient reaction for the preparation of $\gamma-\mathrm{Fe}_{2} \mathrm{O}_{3}$ was discovered and has been expanded to the preparation of
$\gamma-\mathrm{Fe}_{2} \mathrm{O}_{3}, \mathrm{Mn}_{2} \mathrm{O}_{3}, \mathrm{Mn}_{3} \mathrm{O}_{4}$, and $\mathrm{Cr}_{2} \mathrm{O}_{3}$. The results presented here demonstrate (with varying success) the ability to extend this procedure to prepare nanocrystals of the late first-row transition metal oxides.

During the past decade, a number of metal oxides have been prepared from metal acetylacetonates. Several of the oxide nanoparticles prepared from $\mathrm{M}(\mathrm{acac})_{x}$ precursors are $\mathrm{TiO}_{2}, \gamma-\mathrm{Fe}_{2} \mathrm{O}_{3} / \mathrm{Fe}_{3} \mathrm{O}_{4}, \gamma-\mathrm{Ga}_{2} \mathrm{O}_{3}, \mathrm{ZnO}, \mathrm{In}_{2} \mathrm{O}_{3}, \mathrm{~V}_{2} \mathrm{O}_{3}, \mathrm{Nb}_{2} \mathrm{O}_{5}$, $\mathrm{Ta}_{2} \mathrm{O}_{5}, \mathrm{HfO}_{2}$, and $\mathrm{SnO}_{2}$ [11-13, 15-20]. One excellent method, pioneered by Niederberger and coworkers [5], using only $\mathrm{M}(\mathrm{acac})_{x}$ precursors and benzylamine solvent has produced many of the aforementioned metal oxides. Sun and coworkers [21] have synthesized $\mathrm{Fe}_{3} \mathrm{O}_{4}$ by heating $\mathrm{Fe}(\mathrm{acac})_{3}$ with oleylamine, oleic acid, and 1,2-hexadecanediol. In comparison to other acetylacetonates or acetate precursors, $\mathrm{Fe}(\mathrm{acac})_{3}$ is less costly and the nanoparticle products are of comparable uniformity and monodispersity. Metal acetylacetonates also possess low moisture sensitivity, rendering them less susceptible to hydrolysis, which is a common disadvantage of metal alkoxides and halides [22].

Capping ligands on nanoparticles have several purposes. They provide a dense monolayer, which coats the nanoparticle surface that prevents aggregation and controls nanoparticle growth. Capping ligands have the potential to modify the surface for further use in application-based chemistry. However, high solution temperatures $\left(>200^{\circ} \mathrm{C}\right.$, typically 300 $400^{\circ} \mathrm{C}$ ) or hydrothermal conditions are generally required in 
crystalline metal oxide nanoparticle syntheses, which limits ligand selection to a small set that can withstand temperatures over $200^{\circ} \mathrm{C}$. For this reason, there is a focus on developing low-temperature nanoparticle synthetic procedures [23]. In addition, many of the more commonly used ligands, such as oleic acid and trioctylphosphine oxide (TOPO), have hydrophobic tails and limit solubility of the nanoparticles to nonpolar solvents. Given these limitations, the challenge is to design a surface ligand that can provide a desired surface chemistry and functionality and yet survives the harsh reaction conditions. The ability to tune solubility by altering surface chemistry would gear metal oxide nanoparticles towards technological applications. Currently, ligand-exchange is often used to alter the solubility of nanoparticles postsynthesis [24]. There are many ligands that have low volatility and can form covalent or ionic binding interactions with oxide surfaces; however, only a few, such as oleic acid, deliver highly monodisperse and uniform nanoparticles. Part of the research described here seeks to overcome these obstacles by screening for new ligands that could tune the solubility of nanoparticles beyond the realm of organic solvents.

\section{EXPERIMENTAL METHODS}

\subsection{Synthesis of iron oxide nanoparticles}

Unless otherwise noted, iron(III) acetylacetonate $(2 \mathrm{mmol})$ (Strem Chemicals, Inc., Newburyport, Mass, USA) was combined with $20 \mathrm{~mL}$ of surfactant/solvent (2-acetyl pyridine (AP), $p$-anisaldehyde (PA), $\gamma$-butyrolactone (BL), ethylene carbonate (EC), or 1-formyl piperidine (FP), all obtained from Sigma-Aldrich Inc, Milwakee, Wis, USA) and refluxed for 30 minutes under positive $\mathrm{N}_{2}$ pressure. The solvent also acts as the surfactant, forming a protective layer on the nanoparticle surface. The solution was cooled to room temperature, dissolved in hexanes to disperse the nanoparticles, and then centrifuged at $3800 \mathrm{rpm}$ for 10 minutes. The workup for each reaction product is dependent upon the solvent used. When 2-acetyl pyridine or ethyl salicylate was the solvent, the nanoparticles were precipitated from solution with water, centrifuged for 10 minutes to collect the precipitate, which was then redispersed in chloroform. Nanoparticles prepared with $p$-anisaldehyde or $\gamma$-butyrolactone were collected by precipitating with hexanes and redispersed in ethanol or acetone. Ethylene carbonate solvent requires precipitating nanoparticles with ethanol, centrifuging to collect the precipitate, which is then dispersed in chloroform. With 1 -formyl piperidine, the nanoparticles were isolated by precipitation with hexanes and were dispersed in water. TEM imaging to determine morphology, and phase determination by XRD (Inel X-ray diffractometer) were performed to characterize the samples. Images of the nanoparticles were taken on a JEOL cx100 transmission electron microscope (TEM) at $100 \mathrm{kV}$ with a charge-coupled device (CCD) camera attachment. TEM samples were prepared by drying solvent dispersions of the nanoparticles onto carbon-backed 400-mesh $\mathrm{Cu}$ grids followed by drying under vacuum at room temperature.

\subsection{Synthesis of chromium oxide nanoparticles}

Chromium oxide $\left(\mathrm{Cr}_{2} \mathrm{O}_{3}\right)$ nanoparticles were prepared by heating $\mathrm{Cr}(\mathrm{III})$ acetylacetonate $(1 \mathrm{mmol}, 0.35 \mathrm{~g}$ ) (Strem Chemicals, Inc.) with $20 \mathrm{~mL}$ acetone (or cyclohexanone or ethanol) in a Teflon-lined Parr acid-digestion bomb at $200^{\circ} \mathrm{C}$ for 72 hours to one week. The bomb was cooled to RT before opening. The product was a dark green precipitate in a green solution that was dissolved in chloroform and centrifuged for 10 minutes. A green solid precipitated and was dried for 12 hours under vacuum, followed by annealing for 4 hours at $500^{\circ} \mathrm{C}$ in air. The product is able to form a semistable suspension in chloroform with the help of sonication. Percent yield increased with longer durations of heating. The dark green material was characterized by TEM, XRD, and elemental analysis.

\subsection{Synthesis of manganese oxide nanoparticles}

Manganese oxide $\left(\mathrm{Mn}_{2} \mathrm{O}_{3}\right)$ nanoparticles were synthesized by heating $\mathrm{Mn}(\mathrm{III})$ acetylacetonate ( $1 \mathrm{mmol}, 0.35 \mathrm{~g}$ ) in $20 \mathrm{~mL}$ acetone or ethanol in a Teflon-lined Parr acid-digestion bomb at $200^{\circ} \mathrm{C}$ for a minimum of 72 hours. The dark product solution was dispersed in chloroform and centrifuged for 10 minutes. The black precipitate was isolated and dried at RT under vacuum for 12 hours, followed by calcination at $500^{\circ} \mathrm{C}$ for 4 hours. The product was characterized by XRD, TEM, and elemental analysis. $\mathrm{Mn}_{3} \mathrm{O}_{4}$ nanoparticles were prepared by heating $\mathrm{Mn}$ (II) acetylacetonate $(1 \mathrm{mmol}$, $0.25 \mathrm{~g}$ ) in cyclohexanone in a Parr acid-digestion bomb, lined with Teflon for 4 days at $200^{\circ} \mathrm{C}$. The product was collected by adding chloroform to the product solution and centrifuged for 10 minutes. The black precipitate was collected and dried under vacuum for 12 hours at RT.

\section{RESULTS AND DISCUSSION}

Metal acetylacetonate precursors are not as common as metal alkoxides or metal halides for the synthesis of metal oxide nanoparticles, despite the fact that they are widely available commercially and are inexpensive. The $\beta$-diketonate bidentate ligands coordinate to the metal center strongly, and are believed to provide for more controlled reaction rates than monodentate ligands in the synthesis of metal oxide nanoparticles [22].

Magnetite $\left(\mathrm{Fe}_{2} \mathrm{O}_{3}\right)$ nanoparticles were prepared conveniently and rapidly by heating $\mathrm{Fe}(\mathrm{acac})_{3}$ in one of a number of polar, high boiling point solvents. The solvents also act as capping ligands, providing experimental simplicity and convenience, and were selected based on several criteria. High temperatures are required for this reaction and therefore a high boiling point is imperative in the solvent. Since there are a large number of capping ligands that are capable of providing solubility in nonpolar organic solvents, solvents with a stronger polarity were chosen, in an effort to provide solubility in more polar and aqueous solvents. Carbonyl groups are known to interact strongly with the metal oxide surfaces [25], therefore solvents containing carbonyls were selected. The capping ligands/solvents selected are shown in Figure 1. The 


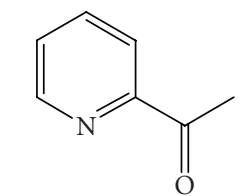

2-acetylpyridine (AP) bp $188^{\circ} \mathrm{C}$

(a)

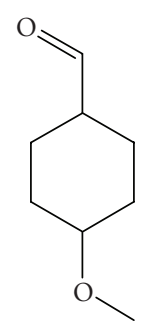

p-anisaldehyde (PA) bp $250^{\circ} \mathrm{C}$

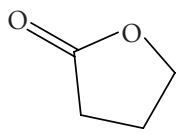

$\gamma$-butyrolactone (BL) bp $204^{\circ} \mathrm{C}$

(b)

(c)<smiles>O=C1OCCO1</smiles>

Ethylene carbonte (EC) bp $250^{\circ} \mathrm{C}$<smiles>O=CN1CCCCC1</smiles>

1-formylpiperidine (FP) bp $220^{\circ} \mathrm{C}$

(e)

FIGURE 1: Capping ligands/solvents chosen for nanoparticle synthesis. All solvents have carbonyl groups to bind to the metal oxide surface, and high boiling points that allow them to survive high reaction temperatures.
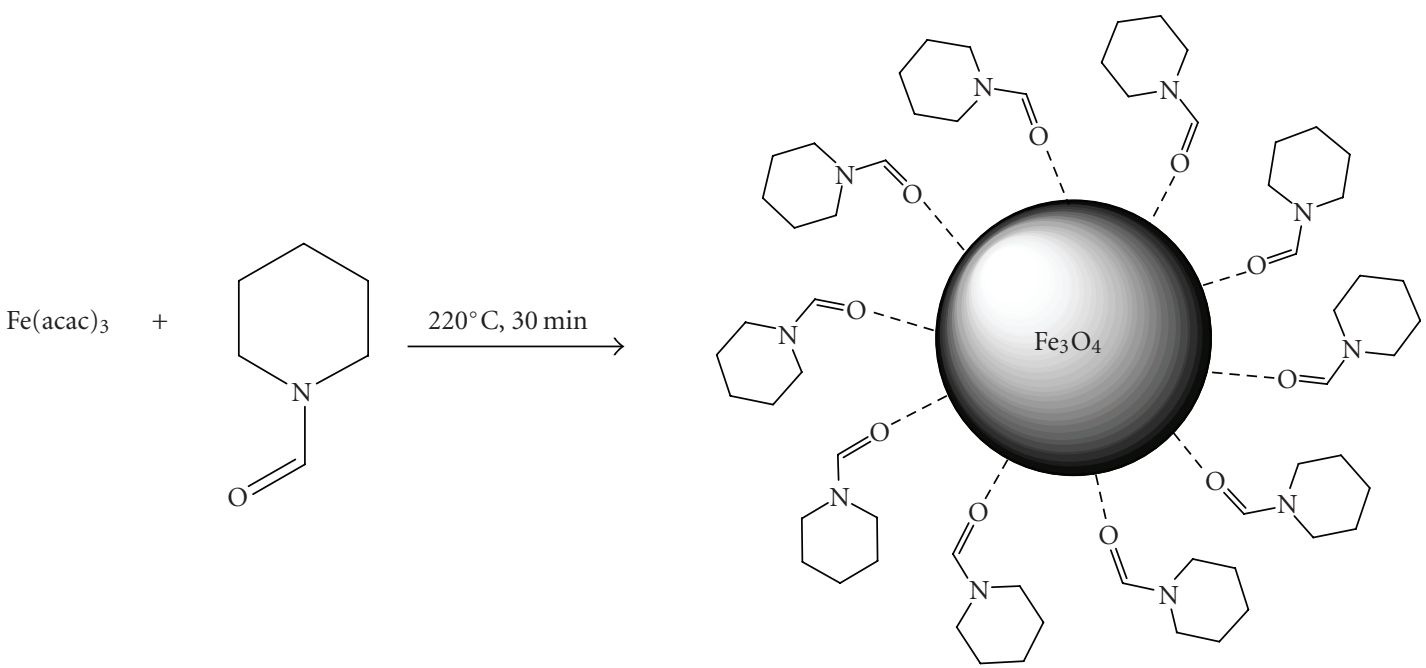

FIGURE 2: Synthesis of water-soluble iron oxide nanoparticles by heating Fe(acac $)_{3}$ in 1-formylpiperidine solvent. The 1-formylpiperidine is proposed to bind to the metal oxide surface through the carbonyl group.

route developed is very short and proceeds rapidly. Under favorable conditions, the reaction can be completed within one hour. A reaction scheme illustrating the proposed binding of FP to the surface of $\gamma-\mathrm{Fe}_{2} \mathrm{O}_{3}$ nanoparticles is shown in Figure 2.

TEM images of $\gamma-\mathrm{Fe}_{2} \mathrm{O}_{3}$ nanoparticles prepared in different solvents are shown in Figure 3. The average diameter of the nanoparticles was determined from the TEM image and ranged from 6 to $55 \mathrm{~nm}$, and average diameter was found to be solvent-dependent. Average nanoparticle diameters are as follows: 2 -acetylpyridine $(6-10 \mathrm{~nm}), p$-anisaldehyde (6$14 \mathrm{~nm}), \gamma$-butyrolactone (9-12 nm), ethylene carbonate (5$51 \mathrm{~nm})$, and 1-formyl piperidine (18-55 nm).

Nanoparticles prepared in 2-acetylpyridine (Figure 3(a)) are mostly spherical and cubic in shape; however, $p$-anisaldehyde (Figure 3(b)) produces a biomodal size distribution of spherical nanoparticles. Iron oxide nanoparticles prepared in $\gamma$-butyrolactone (Figure 3(c)) were difficult to image with TEM, but appear to be spherical in shape. Hexago- nal nanoparticles arise (Figure 3(d)) when ethylene carbonate is the solvent. Interestingly, nanoparticles prepared in 1-formylpiperidine (Figure 3(e)) are nonuniform in shape; however, they are soluble in water. Ethyl salicylate and propylene carbonate solvents were also tested; however, no nanoparticles were observed by TEM.

Products were also characterized by X-ray diffraction and found to be highly crystalline. The reflections in the diffraction pattern correspond to $\gamma-\mathrm{Fe}_{2} \mathrm{O}_{3}$ (JCPDS 39-1346); however, $\mathrm{Fe}_{3} \mathrm{O}_{4}$ has a nearly identical diffraction pattern and may be present. The low angle reflections, (210) and (211), are a sign that $\gamma-\mathrm{Fe}_{2} \mathrm{O}_{3}$ is present as well. An example of the X-ray diffraction pattern obtained during this method of preparation is shown in Figure 4. All were superimposable, and therefore only one is shown.

One important goal of this research was to tune the solubility of iron oxide nanoparticles in order to make them more readily used in applications that require polar or aqueous solvents. We found that nanoparticles capped with AP 


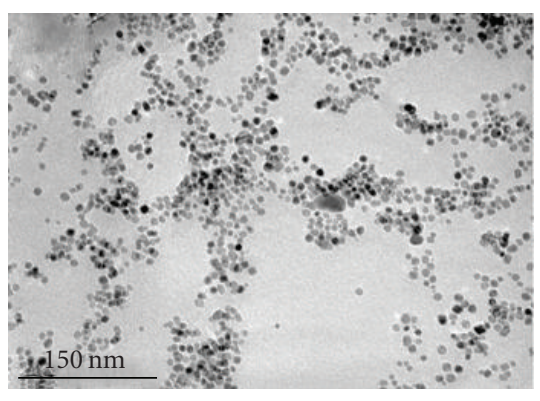

(a)

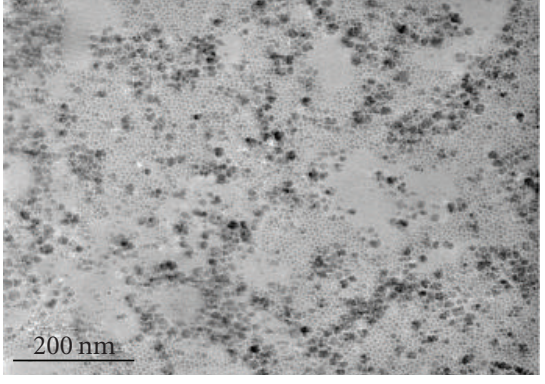

(b)

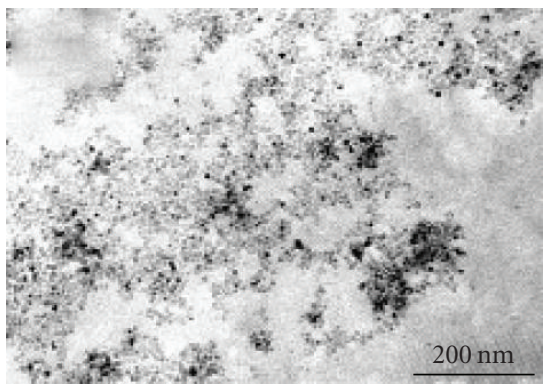

(c)

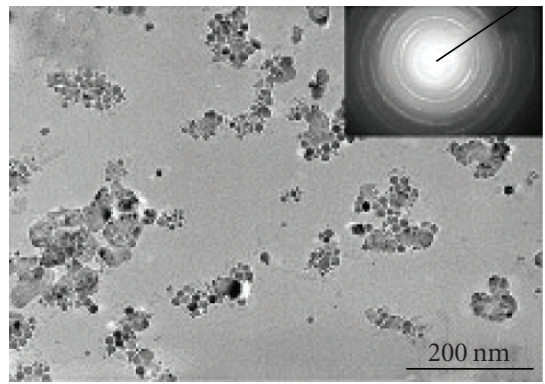

(d)

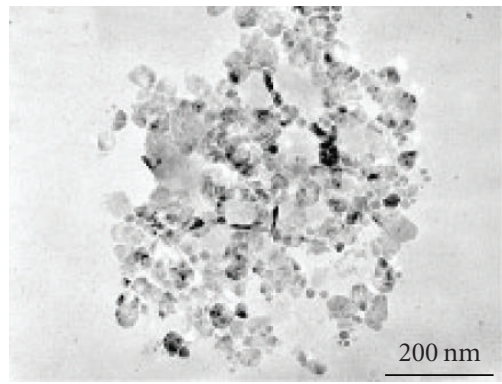

(e)

FIGURE 3: TEM images of solvent-dispersible $\gamma$ - $\mathrm{Fe}_{2} \mathrm{O}_{3}$ nanoparticles prepared with various solvents; 2-acetylpyridine (a), p-anisaldehyde (b), $\gamma$-butyrolactone (c), ethylene carbonate (d), and 1-formylpiperidine (e).

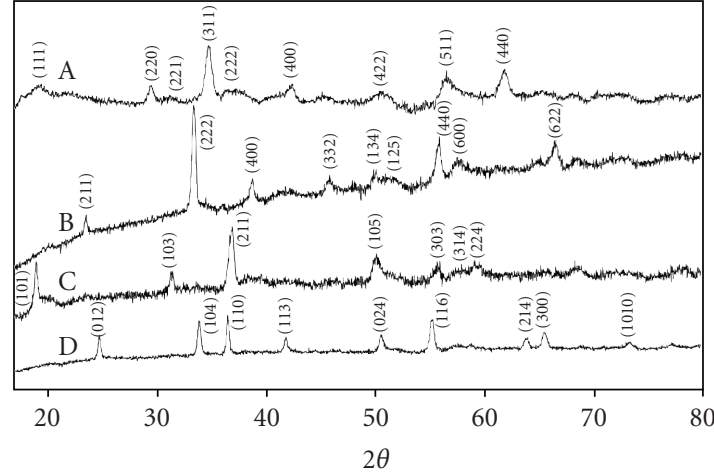

Figure 4: XRD patterns of nanoparticulate $\gamma$ - $\mathrm{Fe}_{2} \mathrm{O}_{3}$ (A), $\mathrm{Mn}_{2} \mathrm{O}_{3}$ (B), $\mathrm{Mn}_{3} \mathrm{O}_{4}$ (C), and $\mathrm{Cr}_{2} \mathrm{O}_{3}$ (D).

and EC are soluble in nonpolar solvents such as chloroform; however, iron oxide nanoparticles capped with PA or BL are soluble in highly polar solvents like ethanol or acetone. Even more exciting is the fact that nanoparticles capped with FP are soluble in water.

Oleic acid is commonly used as a capping ligand in the synthesis of iron oxide nanoparticles. The most widely used method was developed by the talented Hyeon and coworkers [8], and uses a $\mathrm{Fe}(\mathrm{CO})_{5}$ precursor. Iron pentacarbonyl is highly toxic, air sensitive, and also much more expensive than $\mathrm{Fe}(\mathrm{acac})_{3}$. We prepared iron oxide nanocrystals by refluxing $\mathrm{Fe}$ (III) acetylacetonate in oleic acid. Fe(III) acety- lacetonate $(2 \mathrm{mmol})$ was heated to $210^{\circ} \mathrm{C}$ in $20 \mathrm{~mL}$ oleic acid for approximately 30 minutes. The temperature was increased to $300^{\circ} \mathrm{C}$ and stirred at that temperature for one hour. Maintaining one temperature, for example, $200^{\circ} \mathrm{C}$ or $300^{\circ} \mathrm{C}$, did not produce nanoparticles of comparable quality to those produced by temperature ramping. Characterization by TEM shows that the particles are highly monodisperse and uniform in shape. The average size is $10 \mathrm{~nm}$ (Figure 5). The nanoparticles are spherical in shape and self-organized in two dimensions on a TEM grid. These nanoparticles were characterized as $\mathrm{Fe}_{1-\mathrm{x}} \mathrm{O}$ by XRD, which presumably can be further oxidized to $\mathrm{Fe}_{3} \mathrm{O}_{4}$ and $\gamma$ - $\mathrm{Fe}_{2} \mathrm{O}_{3}$ with additional heating. This reaction works very well and produces highly monodisperse nanoparticles.

\section{SYNTHESIS OF $\mathrm{Mn}_{2} \mathrm{O}_{3}$ AND $\mathrm{Mn}_{3} \mathrm{O}_{4}$ NANOPARTICLES}

Manganese acetylacetonate precursors were explored to determine whether other transition metal oxide nanoparticles could also be prepared by the method described to prepare iron oxide nanoparticles. Manganese can exist in various oxidation states, with several common manganese oxides, including $\mathrm{MnO}, \mathrm{Mn}_{2} \mathrm{O}_{3}$, and $\mathrm{Mn}_{3} \mathrm{O}_{4}$.

$\mathrm{Mn}_{2} \mathrm{O}_{3}$ and $\mathrm{Mn}_{3} \mathrm{O}_{4}$ nanoparticles were synthesized simply by heating either $\mathrm{Mn}(\mathrm{acac})_{3}$ or $\mathrm{Mn}(\mathrm{acac})_{2}$ in acetone in a steel autoclave for more than 72 hours. When $\mathrm{Mn}(\text { acac })_{3}$ and acetone were combined in a steel autoclave and heated in a $200^{\circ} \mathrm{C}$ oven for 9 days and the dark brown powder annealed in air at $500^{\circ} \mathrm{C}$ for 5 hours, the XRD (Figure 4) 


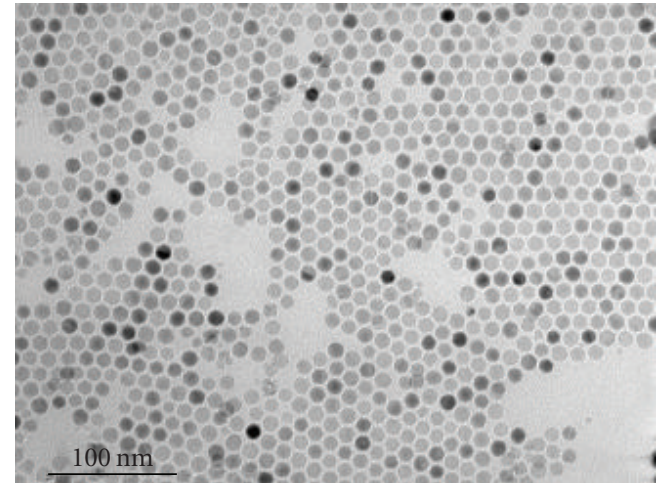

Figure 5: TEM of $\mathrm{Fe}_{1-\mathrm{x}} \mathrm{O}$ nanoparticles. Average size is $10 \mathrm{~nm}$.

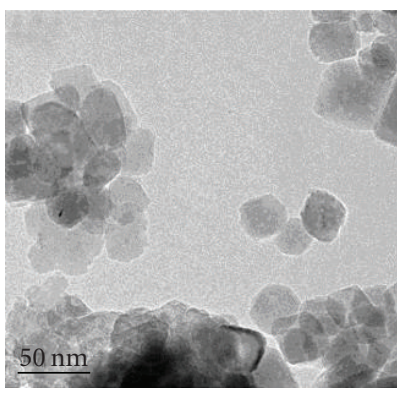

(a)

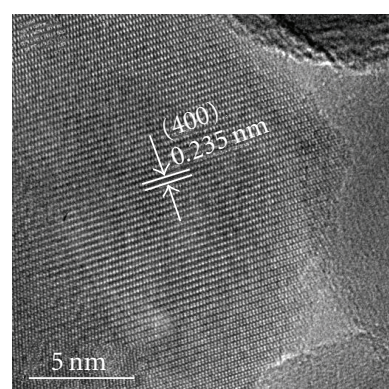

(b)
Figure 6: HRTEM of $\mathrm{Mn}_{2} \mathrm{O}_{3}$ nanoparticles at (a) 60000 and (b) 600000 magnification.

showed the product to be nanocrystalline $\mathrm{Mn}_{2} \mathrm{O}_{3}$. The yield for this reaction was $62 \%$, which is an excellent yield for a metal oxide nanoparticle synthesis. TEM and HRTEM of annealed $\mathrm{Mn}_{2} \mathrm{O}_{3}$ nanoparticles are shown in Figure 6, respectively. The nanoparticles are an average of $35 \mathrm{~nm}$ in diameter, as confirmed by the measurement in the TEM and the Scherrer equation from the (222) peak in the XRD pattern.

The products were amorphous postsynthesis (determined by XRD) and were annealed for 5 hours at $500^{\circ} \mathrm{C}$. After annealing, the $\mathrm{X}$-ray diffraction pattern (Figure 4) proved that the black powder was indeed $\mathrm{Mn}_{2} \mathrm{O}_{3}$, with all major reflections assigned to that structure (JCPDS 71-0636). The nanoparticles are spherical and cubic in shape. Elemental analysis was performed to determine the percent manganese in this sample and further confirmed it as $\mathrm{Mn}_{2} \mathrm{O}_{3}$. Experimentally, the sample contained $69.6 \% \mathrm{Mn}$, which is the expected theoretical weight percent of $\mathrm{Mn}$ in $\mathrm{Mn}_{2} \mathrm{O}_{3}$. Based on the XRD and ICP results, it is concluded that the method developed produces phase-pure $\mathrm{Mn}_{2} \mathrm{O}_{3}$.

$\mathrm{Mn}_{3} \mathrm{O}_{4}$ nanoparticles were formed when $\mathrm{Mn}(\mathrm{acac})_{2}$ was heated with cyclohexanone in a Parr acid-digestion bomb at $200^{\circ} \mathrm{C}$ for 4 days. The product was isolated by centrifugation and found to be amorphous by XRD. The dark powder was annealed at $500^{\circ} \mathrm{C}$ for 5 hours and examined by XRD, which showed it to be crystalline. Further characterization by TEM revealed that the nanoparticles are spherical; however,

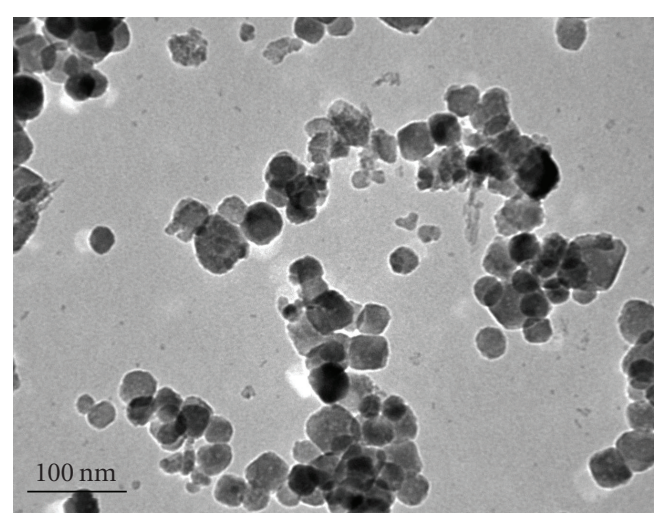

Figure 7: Transmission electron micrograph of $\mathrm{Mn}_{3} \mathrm{O}_{4}$ nanoparticles prepared from $\mathrm{Mn}(\mathrm{acac})_{2}$.

there are several cubic-shaped crystallites as well, as shown in Figure 7. The annealed material was identified as $\mathrm{Mn}_{3} \mathrm{O}_{4}$ by XRD (JCPDS 24-0734) (Figure 4). Calculation of average nanoparticle diameter using the width of the (211) peak in the Scherrer equation gives an average diameter of $11.4 \mathrm{~nm}$.

In summary, manganese oxide nanoparticles can be prepared from both $\mathrm{Mn}(\mathrm{acac})_{2}$ and $\mathrm{Mn}(\mathrm{acac})_{3}$. Acetone, cyclohexanone, and also ethanol were used as solvents and, in addition to the acac ligands, provide potential sources of oxygen. The starting materials (with the exception of cyclohexanone) are environmentally benign and inexpensive. The method of preparation is simple, and products require a convenient workup postreaction.

\section{SYNTHESIS OF $\mathrm{Cr}_{2} \mathrm{O}_{3}$ NANOPARTICLES}

Synthesis of $\mathrm{Cr}_{2} \mathrm{O}_{3}$ nanoparticles has been rarely reported in the literature with some notable exceptions [26-30]. Chromic oxide has a wide variety of applications as green pigments [31], catalysts [32], and coating materials for thermal protection [33]. The lack of simple methods to prepare this useful material led us to pursue its preparation by way of $\mathrm{Cr}(\mathrm{acac})_{3}$.

Chromium oxide nanoparticles were prepared by a procedure analogous to that described above for manganese oxide nanoparticles. $\mathrm{Cr}(\mathrm{acac})_{3}$ and acetone were combined in a Teflon-lined Parr acid-digestion bomb and heated for 3 days at $200^{\circ} \mathrm{C}$. $\mathrm{Cr}(\mathrm{acac})_{3}$ sublimes at relatively low temperatures $\left(100^{\circ} \mathrm{C}\right)$ and therefore the reactions were performed in bombs to prevent loss of reagent. The product solution was green and contained a dark green precipitate; the latter was isolated by centrifugation followed by drying under vacuum. The solid product was a deep green powder.

The $\mathrm{Cr}_{2} \mathrm{O}_{3}$ nanoparticles prepared by this method are spherical, polydisperse, and amorphous as determined by XRD (JCPDS 85-0869) (Figure 4) and TEM (Figure 8). The green powder product was annealed in a $500^{\circ} \mathrm{C}$ furnace overnight and converted to crystalline $\mathrm{Cr}_{2} \mathrm{O}_{3}$ as deduced from the XRD pattern (Figure 4). After annealing the powder was very dark green, almost black, and was soluble in 


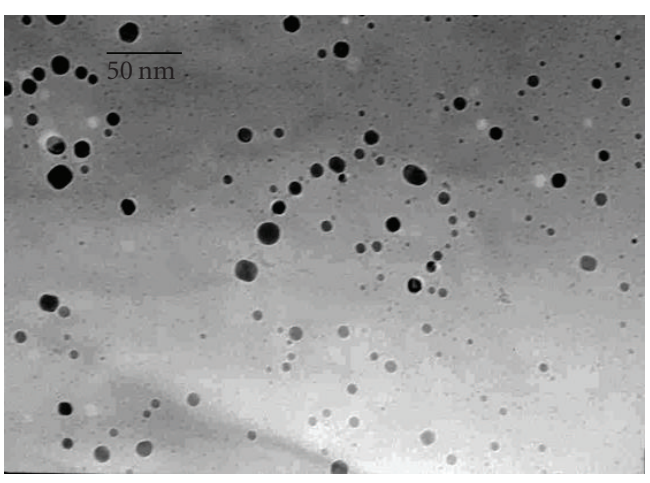

FIgURE 8: TEM of $\mathrm{Cr}_{2} \mathrm{O}_{3}$ nanoparticles.

chloroform. Average crystal size was $18.5 \mathrm{~nm}$, determined using the Scherrer equation.

The annealed powder was further analyzed by elemental analysis at Galbraith Laboratories to determine the percent $\mathrm{Cr}$ content. The sample prepared in acetone solvent was found to have $64.1 \%$ chromium, in reasonable agreement with a calculated content of pure $\mathrm{Cr}_{2} \mathrm{O}_{3}(68.4 \% \mathrm{Cr}$, some organic may be present), and consistent with the XRD analysis.

A variety of other solvents (all containing oxygen) were explored to see if product yields, shape, morphology, or size distribution changed as the solvent species changed. These solvents including benzaldehyde, cyclohexanone, ethanol, and tetrahydrofuran were used in place of acetone; however, the shape of the nanoparticle was not uniform. Benzaldehyde and THF did not produce $\mathrm{Cr}_{2} \mathrm{O}_{3}$, as determined by XRD, even after annealing, but cyclohexanone and ethanol did. The particles formed in THF are aggregated in the TEM and the sample was obtained in low yield. Ethanol produced micron-size spherical particles, and cyclohexanone gave rise to nonuniform-shaped chromic oxide. XRD analysis of the product obtained from the reaction of $\mathrm{Cr}(\mathrm{acac})_{3}$ in benzaldehyde could not be assigned to any of the common $\mathrm{Cr}_{x} \mathrm{O}_{y}$ structures. TEM images of $\mathrm{Cr}_{2} \mathrm{O}_{3}$ prepared in other solvents are shown in the supporting information.

\section{CONCLUSIONS}

A general method for the synthesis of metal oxide nanoparticles has been developed. Metal acetylacetonate precursors are relatively environmentally friendly, and can be used to prepare metal oxide nanoparticles by simple, straightforward methods using only a polar, oxygen-containing solvent and by applying heat. $\gamma$ - $\mathrm{Fe}_{2} \mathrm{O}_{3}, \mathrm{Cr}_{2} \mathrm{O}_{3}, \mathrm{Mn}_{2} \mathrm{O}_{3}$, and $\mathrm{Mn}_{3} \mathrm{O}_{4}$ can be prepared from their $\mathrm{M}(\mathrm{acac})_{x}$ precursors. Maghemite, $\gamma$ $\mathrm{Fe}_{2} \mathrm{O}_{3}$, of varied solubility can be obtained by preparing in different solvents/surfactants. These materials were characterized by TEM, XRD, and elemental analysis.

\section{ACKNOWLEDGMENTS}

This work was supported primarily by the MRSEC Program of the National Science Foundation under Award DMR-
0213574 and CHE-04-15516 at Columbia University. Stephen O'Brien is very grateful for the support from an NSF CAREER award, DMR-0348938. Amanda L. Willis also acknowledges financial support from an NSF GK-12 fellowship.

\section{REFERENCES}

[1] D. K. Kim, Y. Zhang, J. Kehr, T. Klason, B. Bjelke, and M. Muhammed, "Characterization and MRI study of surfactantcoated superparamagnetic nanoparticles administered into the rat brain," Journal of Magnetism and Magnetic Materials, vol. 225, no. 1-2, pp. 256-261, 2001.

[2] B. O'Regan and M. Grätzel, "A low-cost, high-efficiency solar cell based on dye-sensitized colloidal $\mathrm{O}_{2}$ films," Nature, vol. 353, no. 6346, pp. 737-740, 1991.

[3] E. R. Stobbe, B. A. de Boer, and J. W. Geus, "The reduction and oxidation behaviour of manganese oxides," Catalysis Today, vol. 47, no. 1-4, pp. 161-167, 1999.

[4] M. I. Zaki, M. A. Hasan, and L. Pasupulety, "Influence of $\mathrm{CuO}_{x}$ additives on $\mathrm{CO}$ oxidation activity and related surface and bulk behaviours of $\mathrm{Mn}_{2} \mathrm{O}_{3}, \mathrm{Cr}_{2} \mathrm{O}_{3}$ and $\mathrm{WO}_{3}$ catalysts," Applied Catalysis A, vol. 198, no. 1-2, pp. 247-259, 2000.

[5] N. Pinna, G. Garnweitner, M. Antonietti, and M. Niederberger, "A general nonaqueous route to binary metal oxide nanocrystals involving a $\mathrm{C}-\mathrm{C}$ bond cleavage," Journal of the American Chemical Society, vol. 127, no. 15, pp. 5608-5612, 2005.

[6] J. Rockenberger, E. C. Scher, and A. P. Alivisatos, "A new nonhydrolytic single-precursor approach to surfactant-capped nanocrystals of transition metal oxides," Journal of the American Chemical Society, vol. 121, no. 49, pp. 11595-11596, 1999.

[7] S. O'Brien, L. Brus, and C. B. Murray, "Synthesis of monodisperse nanoparticles of barium titanate: toward a generalized strategy of oxide nanoparticle synthesis," Journal of the American Chemical Society, vol. 123, no. 48, pp. 12085-12086, 2001.

[8] T. Hyeon, S. S. Lee, J. Park, Y. Chung, and H. B. Na, "Synthesis of highly crystalline and monodisperse maghemite nanocrystallites without a size-selection process," Journal of the American Chemical Society, vol. 123, no. 51, pp. 12798-12801, 2001.

[9] Q. Huang and L. Gao, "A simple route for the synthesis of rutile $\mathrm{TiO}_{2}$ nanorods," Chemistry Letters, vol. 32, no. 7, pp. 638639, 2003.

[10] N. Pinna, G. Garnweitner, M. Antonietti, and M. Niederberger, "Non-aqueous synthesis of high-purity metal oxide nanopowders using an ether elimination process," Advanced Materials, vol. 16, no. 23-24, pp. 2196-2200, 2004.

[11] N. Pinna, G. Neri, M. Antonietti, and M. Niederberger, "Nonaqueous synthesis of nanocrystalline semiconducting metal oxides for gas sensing," Angewandte Chemie, vol. 43, no. 33, pp. 4345-4349, 2004.

[12] M. Niederberger, G. Garnweitner, F. Krumeich, R. Nesper, H. Cölfen, and M. Antonietti, "Tailoring the surface and solubility properties of nanocrystalline titania by a nonaqueous in situ functionalization process," Chemistry of Materials, vol. 16, no. 7, pp. 1202-1208, 2004.

[13] M. Niederberger, M. H. Bartl, and G. D. Stucky, "Benzyl alcohol and titanium tetrachloride-a versatile reaction system for the nonaqueous and low-temperature preparation of crystalline and luminescent titania nanoparticles," Chemistry of Materials, vol. 14, no. 10, pp. 4364-4370, 2002. 
[14] S. O'Brien and M. Yin, Synthesis, characterization and properties of nano-sized transistion metal oxides, Ph.D. thesis, 2005.

[15] N. Pinna, M. Antonietti, and M. Niederberger, "A novel nonaqueous route to $\mathrm{V}_{2} \mathrm{O}_{3}$ and $\mathrm{Nb}_{2} \mathrm{O}_{5}$ nanocrystals," Colloids and Surfaces A, vol. 250, no. 1-3, pp. 211-213, 2004.

[16] N. Pinna, G. Garnweitner, M. Antonietti, and M. Niederberger, "A general nonaqueous route to binary metal oxide nanocrystals involving a $\mathrm{C}-\mathrm{C}$ bond cleavage," Journal of the American Chemical Society, vol. 127, no. 15, pp. 5608-5612, 2005.

[17] S. Sun, H. Zeng, D. B. Robinson, et al., "Monodisperse $\mathrm{MFe}_{2} \mathrm{O}_{4}(\mathrm{M}=\mathrm{Fe}, \mathrm{Co}, \mathrm{Mn})$ nanoparticles," Journal of the American Chemical Society, vol. 126, no. 1, pp. 273-279, 2004.

[18] S. Sun and H. Zeng, "Size-controlled synthesis of magnetite nanoparticles," Journal of the American Chemical Society, vol. 124, no. 28, pp. 8204-8205, 2002.

[19] Z. Li, H. Chen, H. Bao, and M. Gao, "One-pot reaction to synthesize water-soluble magnetite nanocrystals," Chemistry of Materials, vol. 16, no. 8, pp. 1391-1393, 2004.

[20] P. D. Cozzoli, A. Kornowski, and H. Weller, "Colloidal synthesis of organic-capped $\mathrm{ZnO}$ nanocrystals via a sequential reduction-oxidation reaction," Physical Chemistry B, vol. 109, pp. 2638-2644, 2005.

[21] N. R. Jana, Y. Chen, and X. Peng, "Size- and shape-controlled magnetic (Cr, Mn, Fe, Co, Ni) oxide nanocrystals via a simple and general approach," Chemistry of Materials, vol. 16, pp. 3931-3935, 2004.

[22] T. Tsuchiya, A. Watanabe, Y. Imai, et al., "Direct conversion of metal acetylacetonates and metal organic acid salts into metal oxides thin films using coating photolysis process with an ArF excimer laser," Japanese Journal of Applied Physics, Part 2: Letters, vol. 38, no. 10 A, pp. L1112-L114, 1999.

[23] W. A. Daoud and J. H. Xin, "Synthesis of single-phase anatase nanocrystallites at near room temperatures," Chemical Communications, no. 16, pp. 2110-2112, 2005.

[24] A. K. Boal, K. Das, M. Gray, and V. M. Rotello, "Monolayer exchange chemistry of $\gamma$ - $\mathrm{Fe}_{2} \mathrm{O}_{3}$ nanoparticles," Chemistry of $\mathrm{Ma}$ terials, vol. 14, no. 6, pp. 2628-2636, 2002.

[25] Z. Li, H. Chen, H. Bao, and M. Gao, "One-pot reaction to synthesize water-soluble magnetite nanocrystals," Chemistry of Materials, vol. 16, no. 8, pp. 1391-1393, 2004.

[26] N. R. Jana, Y. Chen, and X. Peng, "Size- and shape-controlled magnetic (Cr, Mn, Fe, Co, Ni) oxide nanocrystals via a simple and general approach," Chemistry of Materials, vol. 16, no. 20, pp. 3931-3935, 2004.

[27] T. Tsuzuki and P. G. McCormick, "Synthesis of $\mathrm{Cr}_{2} \mathrm{O}_{3}$ nanoparticles by mechanochemical processing," Acta Materialia, vol. 48, no. 11, pp. 2795-2801, 2000.

[28] U. Balachandran, R. W. Siegel, Y. X. Liao, and T. R. Askew, "Synthesis, sintering, and magnetic properties of nanophase $\mathrm{Cr}_{2} \mathrm{O}_{3}$," Nanostructured Materials, vol. 5, no. 5, pp. 505-512, 1995.

[29] D. Vollath, D. V. Szabó, and J. O. Willis, "Magnetic properties of nanocrystalline $\mathrm{Cr}_{2} \mathrm{O}_{3}$ synthesized in a microwave plasma," Materials Letters, vol. 29, no. 4-6, pp. 271-279, 1996.

[30] N. A. Dhas, Y. Koltypin, and A. Gedanken, "Sonochemical preparation and characterization of ultrafine chromium oxide and manganese oxide powders," Chemistry of Materials, vol. 9, no. 12, pp. 3159-3163, 1997.

[31] T. Brock, M. Groteklaes, and P. Mischke, European Coating Handbook, Vincent, Hanover, Germany, 2000.
[32] B. M. Abu-Zied, "Structural and catalytic activity studies of silver/chromia catalysts," Applied Catalysis A, vol. 198, no. 1-2, pp. 139-153, 2000.

[33] P. Berdahl, "Pigments to reflect the infrared radiation from fire," Journal of Heat Transfer, vol. 117, no. 2, pp. 355-358, 1995. 

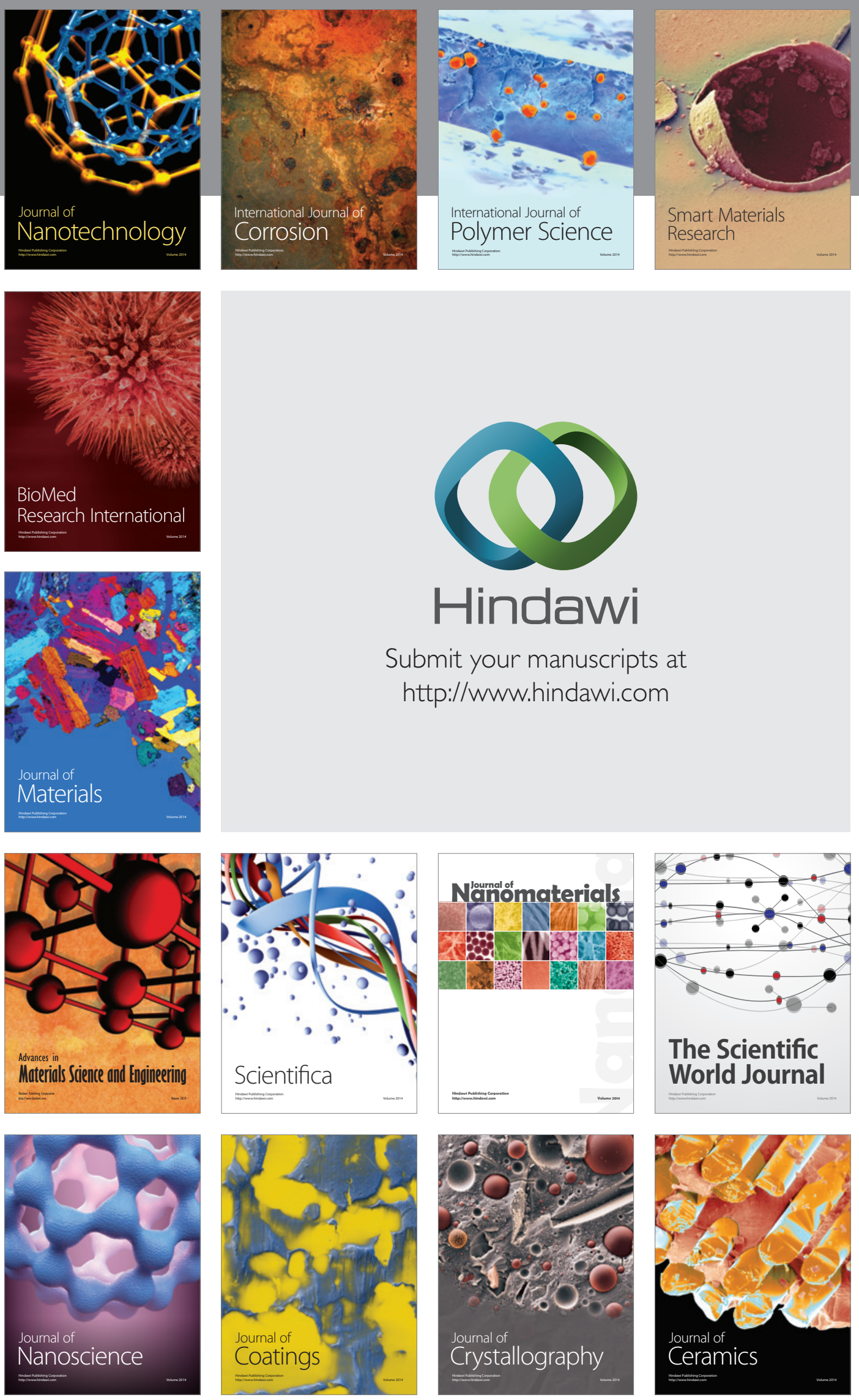

The Scientific World Journal

Submit your manuscripts at

http://www.hindawi.com

\section{World Journal}

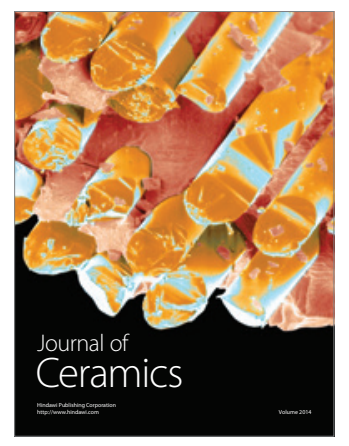

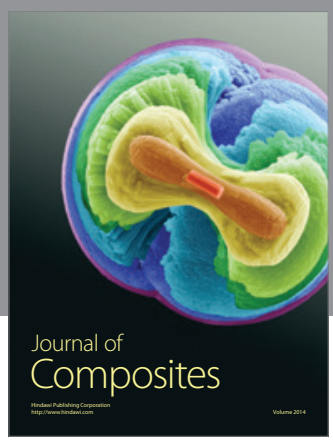
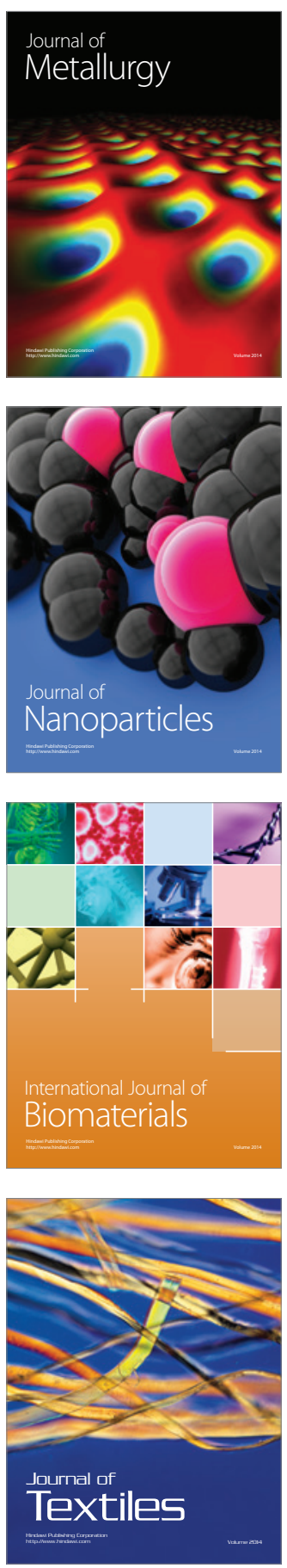